\title{
Functional Genomic Approaches Using the Nematode Caenorhabditis elegans as a Model System
}

\author{
Junho Lee*, Seunghee Nam, Soon Baek Hwang, Mingi Hong, Jae Young Kwon, \\ Kyu Sang Joeng, Seol Hee Im, Jiwon Shim and Moon Cheol Park \\ National Research Laboratory, Department of Biology, Yonsei University, 134 Shinchon, Seoul 120-749, Korea
}

Received 20 December 2003

\begin{abstract}
Since the completion of the genome project of the nematode $C$. elegans in 1998, functional genomic approaches have been applied to elucidate the gene and protein networks in this model organism. The recent completion of the whole genome of $C$. briggsae, a close sister species of $C$. elegans, now makes it possible to employ the comparative genomic approaches for identifying regulatory mechanisms that are conserved in these species and to make more precise annotation of the predicted genes. RNA interference (RNAi) screenings in $\boldsymbol{C}$. elegans have been performed to screen the whole genome for the genes whose mutations give rise to specific phenotypes of interest. RNAi screens can also be used to identify genes that act genetically together with a gene of interest. Microarray experiments have been very useful in identifying genes that exhibit co-regulated expression profiles in given genetic or environmental conditions. Proteomic approaches also can be applied to the nematode, just as in other species whose genomes are known. With all these functional genomic tools, genetics will still remain an important tool for gene function studies in the post genome era. New breakthroughs in C. elegans biology, such as establishing a feasible gene knockout method, immortalized cell lines, or identifying viruses that can be used as vectors for introducing exogenous gene constructs into the worms, will augment the usage of this small organism for genome-wide biology.
\end{abstract}

Keywords: $C$. elegans, C. briggsae, Functional genomics, Micorarray, Proteomics, RNAi screening, Comparative genomics

*To whom correspondence should be addressed.

Tel: 82-2-2123-2663; Fax: 82-2-312-5657

E-mail: leej@yonsei.ac.kr
The Nematode $C$. elegans as a Model Organism

The nematode Caenorhabditis elegans, a free-living soil nematode (Fig. 1), has become one of the typical model organisms for studying gene functions by genetic analyses since the first genetic paper was published in 1974 (Brenner, 1974). Although C. elegans is a simple organism, it shares many of the essential biological characteristics with human biology. The nematode has a conserved mode of development, neuronal functions, cell death, behavior, and aging. C. elegans is only $1 \mathrm{~mm}$ long and is usually grown on small plates seeded with bacteria. All 959 somatic cells of its transparent body are visible with a microscope, and its average life span is only 2-3 weeks. Adding to its simple anatomy and quick development, a small number of chromosomes (only 5 autosomes and a sex

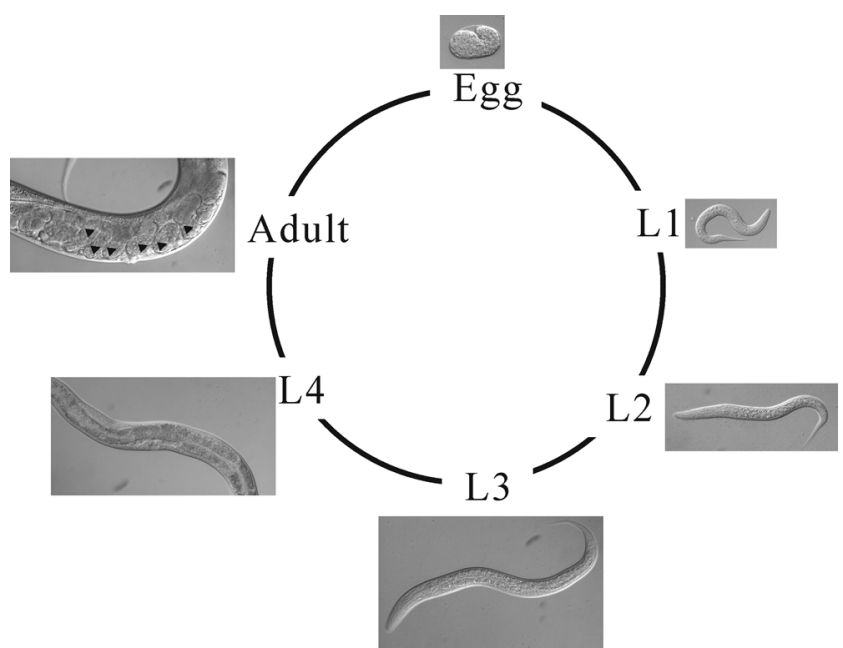

Fig. 1. C. elegans as a model organism. The lifecycle of the nematode $C$. elegans is shown. $C$. elegans undergoes four larval stages to become an adult. An adult hermaphrodite animal, as shown in the figure, is anatomically a female animal that temporarily produces a limited number of sperm as well as eggs. Arrowheads indicate some of the eggs inside the hermaphrodite adult. 
Table 1. Resources for nematode biology

\begin{tabular}{|c|c|c|}
\hline Name & URL & Description \\
\hline WormBase & www.wormbase.org & $\begin{array}{l}\text { The most comprehensive database containing genes to genome } \\
\text { information. }\end{array}$ \\
\hline C. elegans WWW server & elegans.swmed.edu & $\begin{array}{l}\text { The main gate website that links to every available database or } \\
\text { website. It also contains worm breeders gazette, a newsletter that } \\
\text { shows most of the updated information from } C \text {. elegans labs. }\end{array}$ \\
\hline Caenorhabditis Genetics Center & $\begin{array}{l}\text { Biosci.umn.edu/CGC } \\
\text { /CGChomepage.htm }\end{array}$ & $\begin{array}{l}\text { Provides all the nematode strains to researchers around the } \\
\text { world. }\end{array}$ \\
\hline C. elegans genome project, UK & $\begin{array}{l}\text { www.sanger.ac.uk/ } \\
\text { Projects/C_elegans }\end{array}$ & Contains $C$. elegans and $C$. briggsae sequence data \\
\hline C. elegans genome project, USA & genome.wustl.edu & Contains $C$. elegans and $C$. briggsae sequence data \\
\hline Yuji Koharas cDNAs & www.ddbj.nig.ac.jp & DNA Data Bank of Japan \\
\hline WormPD & $\begin{array}{l}\text { www.incyte.com/ } \\
\text { proteome }\end{array}$ & $\begin{array}{l}\text { Commercial database containing most of the updated information } \\
\text { on nematode ORFs. }\end{array}$ \\
\hline The Kim microarray & $\begin{array}{l}\text { cmgm.stanford.edu/ } \\
\sim \text { kimlab }\end{array}$ & Contains the microarray data from the Kim lab. \\
\hline C. elegans $\mathrm{KO}$ consortium & $\begin{array}{l}\text { celeganskoconsortium. } \\
\text { omrf.org }\end{array}$ & $\begin{array}{l}\text { Provides the list of available KO strains, and the list of genes } \\
\text { requested to be knocked out. }\end{array}$ \\
\hline $\begin{array}{l}\text { Korean } C \text {. elegans } \\
\text { community }\end{array}$ & $\begin{array}{l}\text { biology.yonsei.ac.kr/ } \\
\text { elegans }\end{array}$ & The homepage of the Korean nematode biologists \\
\hline
\end{tabular}

chromosome) made this system an ideal system for genetics. In addition to its strong genetics, the recent completion of its complete genome made this simple organism a system of choice for intensive functional genomic approaches. Furthermore, most of the information obtained from various labs is available publicly through the internet (Table 1), which can accelerate collaborative researches throughout the world. In this review, we will discuss how $C$. elegans can be used in diverse aspects of functional genomic experiments.

\section{Comparative Genomics}

Finishing the genome project of a species is not an endpoint of a process, but a start point of new research including functional genomics for elucidating gene networks in the development and functions at the genomic level and comparative genomics for elucidating evolutionarily conserved functions and regulation. Even before finishing the C. elegans genome project, many researchers were interested in the gene structures in a closely related nematode species for comparative purposes. The nematode Caenorhabditis briggsae is a sister species of C. elegans, whose anatomy and most developmental processes are almost identical to those of C. elegans. To our excitement, the complete sequence of the C. briggsae genome was determined in November 2003 and published in the Public Library of Science Biology (Stein et al., 2003). The completion of the two closely related nematode species will enable researchers to elucidate regulatory mechanisms underlying the genes of their interest. Indeed, it has long been assumed that the genome of the two nematodes should contain shared regulatory mechanisms for most of the developmentally important genes, and this was confirmed by many experimental reports. Heschl and Ballie found in 1990 that interspecific cross-hybridizing DNA was primarily restricted to coding regions using a $h s p$-70 gene structure, and proposed that a comparison of the C. elegans and $C$. briggsae sequences would be useful in the detection of potential regulatory and structural elements (Heschl and Baillie, 1990). Thereafter, many reports were published on the comparison of the homologs from the two nematode species (Kuwabara and Shah, 1994; Cui and Han, 2003; Kirouac and Sternberg, 2003). Our recent work on the SNAP-25 gene regulation also revealed the usefulness of the $C$. briggsae genome information (Hwang and Lee, 2003). The SANP-25 gene in C. elegans contains a long first intron, and this feature is also conserved in C. briggsae. Interestingly, the first introns in both species, which were extremely large compared with most $C$. elegans introns, did not show high similarity in the overall nucleotide sequences, but instead there were conserved blocks of nucleotides within the intron (Fig. 2). An examination of the functions of these short stretches of nucleotide that were conserved within the intron led to the discovery of the regulatory elements that are required for the neuronal cell-type specific expression of SNAP-25 in the nematode (Hwang and Lee, 2003).

A caveat still remains to the assumption that the conserved non-coding sequences may be functionally significant: some 
A. Upstream promoter region

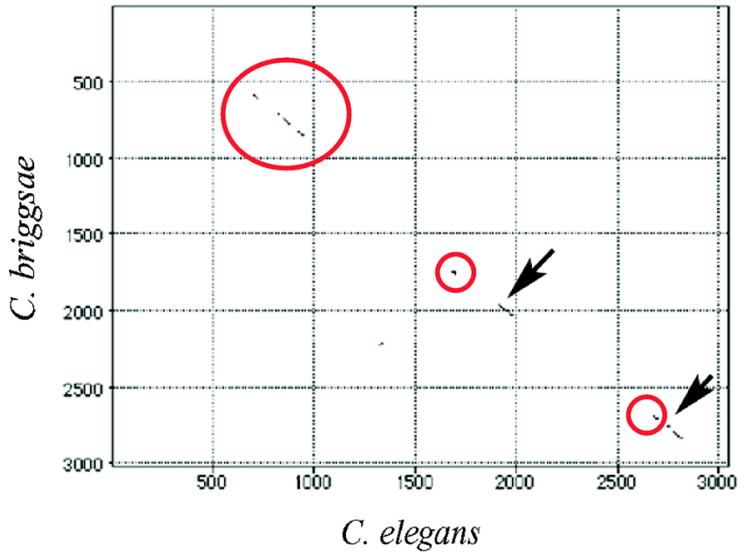

B. The firstintron

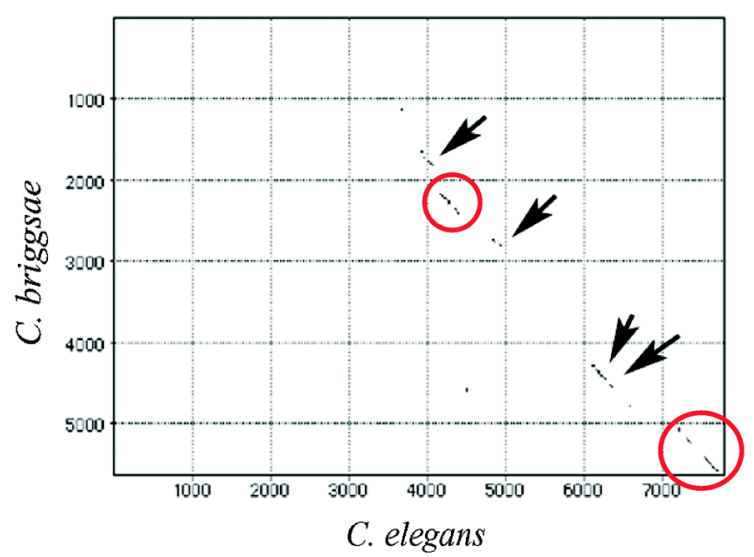

Fig. 2. Conserved sequences in the promoter (A) and the first intron (B) of SNAP-25 versus functionally important blocks of sequences in regulation. The promoter region shows a $13.7 \%$ identity and the first intron shows a $10.3 \%$ identity between the two nematode species. Among the conserved blocks of sequences, some of them (indicated by arrows) are indeed involved in the neuron cell-type specific expression of SNAP-25. Others indicated by the red circles are not.

of the conserved blocks of sequences contain no functional significance, although others do (Fig. 2). To overcome this problem, it would be very helpful to have a complete genome sequence of other nematode species. A comparison of the sequences among three or more closely related species will eliminate most of the false positive regulatory elements, facilitating the narrowing down of the candidate regulatory elements.

\section{RNA Interference and RNAi Screening}

RNA interference is a phenomenon discovered in C. elegans (Fire et al., 1998), and now used as a favorite method of knocking down a gene function in various species. In $C$. elegans, there are three ways to perform RNAi experiments.
First, one can microinject the dsRNA into the animals directly and observe the effects among the progeny that the injected animals lay (Fire et al., 1998). Unlike the microinjection of DNA, in which case it is crucial to deliver the DNA into the syncytial gonad, the microinjection of RNA can be applied to any part of the nematode body. One can inject RNA into the intestine, the hypodermis, as well as into the gonad to see the RNAi effects. This feasibility enables even a novice to perform RNAi experiments because they do not need any sophisticated microinjection skills. A second method involves the feeding of a bacteria that produce dsRNA of interest (Timmons and Fire, 1998). The third way of delivering dsRNA into the nematode is to soak the worms in the RNA solution without injection, nor feeding (Tabara et al., 1998). All three methods give comparable efficiency, thus it is up to the researchers which method they will adopt in their experiments. In order to perform conditional RNAi experiments in which one wants to knockdown a gene function in a specific tissue or at a specific developmental timing, it is possible to introduce into the worms DNA constructs that are designed to produce dsRNA under the control of a tissue-specific or an inducible promoter (Tavernarakis et al., 2000).

With the progress of the RNAi techniques and the completion of the genome project, it has become possible to use RNAi at the genome-wide level. The Arhinger lab constructed an RNAi library of bacteria that produces dsRNA for roughly $86 \%$ of the total open-reading frames (Kamath and Ahringer, 2003). This library is available through MRC. Several labs published the results of the genome-wide RNAi analysis of the $C$. elegans wild-type N2 strain (Fraser et al., 2000; Gonczy et al., 2000; Piano et al., 2000; Tavernarakis et al., 2000; Maeda et al., 2001; Ashrafi et al., 2003; Kamath and Ahringer, 2003; Kamath et al., 2003; Lee et al., 2003). According to the published data, the efficiency of RNAi is about $50 \%$ in the RNAi phenotypes that can be observed for approximately half of the known mutations. Recently, a RNAi analysis in the rrf-3 mutant background was published (Simmer et al., 2003). rrf-3 is a mutation that causes sensitivity to RNAi, thus more phenotypes were observed for the genes that showed no phenotype in the wild-type background. Feeding of the RNAi library to rrf-3 mutants resulted in increasing the number of genes with a phenotype by $23 \%$. All the RNAi phenotypes can be searched on a public database (www.wormbase.org).

A future application of the RNAi screening for functional genomics can be to use RNAi screens in the background of a mutation in the gene of interest for identifying genes that genetically interact with the gene of interest (Fig. 3). For example, if a mutation in a given gene shows no distinct phenotype, one can suspect that there might be redundant genes acting together with the gene. In this case, one can identify genes whose RNAi in the background of the mutation causes severer phenotypes. In other cases, if one uses a reduction-of-function mutation as a genetic background of the 
(A)

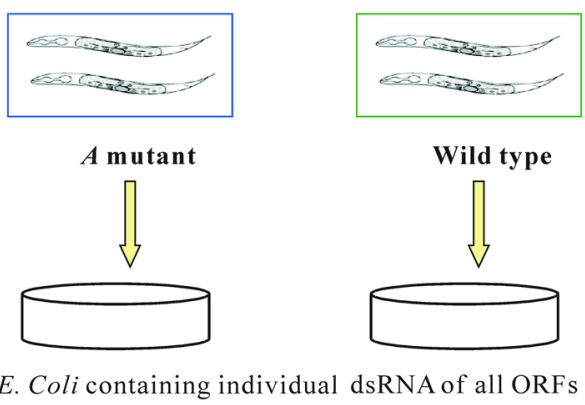

(B)
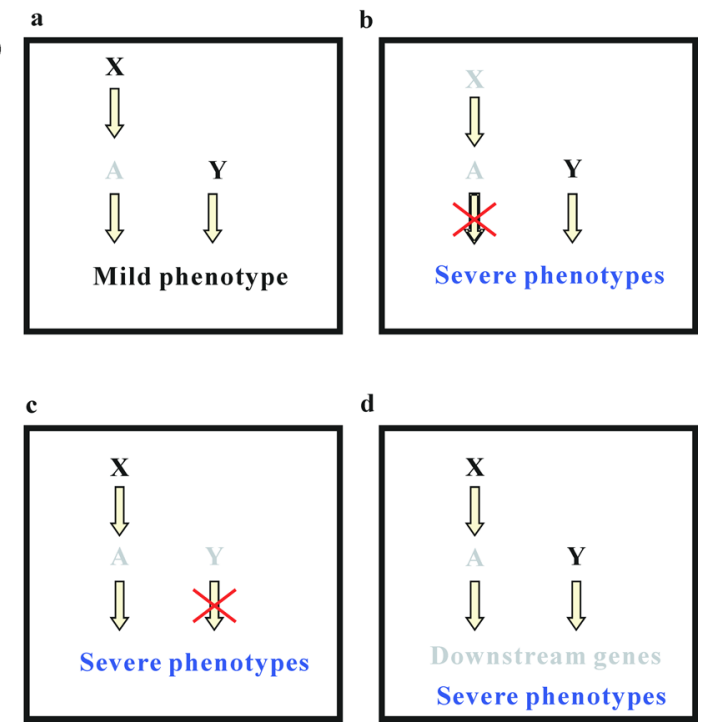

Fig. 3. An RNAi screening scheme for identifying interacting genes. (A) An experimental scheme of an RNAi screen in the background of a mutation in the gene of interest to identify interacting genes. Wild-type animals and mutant animals are grown on the dsRNA-producing bacteria. The genes that show synergistic phenotypes only in the mutant background will be selected. (B) An example of sensitized RNAi screen. This experimental scheme can be used to identify genes that act upstream of, in parallel to, or downstream of the gene A. b-d shows the cases where the genes can be identified in this screen.

RNAi screening, this may sensitize the screening, and mutations in the genes acting upstream of, in parallel to, or downstream of the gene of interest might give a synthetic phenotype (Fig. 3).

\section{Microarray Experiments as a Tool to Identify Co-regulated Genes}

Microarray is one of the most valuable tools that can be obtained from the complete genome information. Micorarray experiments are performed for many purposes, including expression profiling of an organism under a specific condition (for a simplified scheme, see Fig. 4A). There are two types of microarray chips available for the nematode functional genomic approaches. The first microarray was developed by
S. Kim at Stanford University (Reinke et al., 2000). The most recent version of the Kim microarray chip contains about 20,000 ORFs in the form of cDNA. So far, over 600 experiments have been performed, and numerous discoveries were made. For example, Reinke et al. examined the global profile of the germline gene expression using an early version of the cDNA microarray (Reinke et al., 2000). Since then, microarray experiments have been performed in a certain context of biology such as aging, heat shock, specific developmental stages, sexes, and so on (Blumenthal et al., 2002; GuhaThakurta et al., 2002; Reinke, 2002; Romagnolo et al., 2002; Zhang et al., 2002; Link et al., 2003; Murphy et al., 2003; Wang and Kim, 2003). A useful way of analyzing the expression profile of a specific gene in terms of coregulation is to examine its map position on an expression profile terrain map that was suggested by Kim et al. (2001). They assembled data from over 500 C. elegans DNA microarray experiments and grouped co-regulated genes in a three-dimensional expression map that displays correlations of gene expression profiles.

Our lab has also been able to identify several hundred genes that are co-regulated by the exposure to alcohol using the Kim microarrays (Kwon et al., 2004). The nematode shows similar responses to acute ethanol exposure to those observed in humans. We used the $C$. elegans microarray to identify and characterize the genes that are affected by ethanol. We were able to identify over two hundred genes whose transcription level was affected by ethanol. In order to make certain that the genes were really positive, we performed Northern analyses of about 100 candidate genes, and found that over $96 \%$ of the genes behaved similarly in Northern when compared with the microarray data, confirming that the Kim microarray is a very good quality DNA chip. We then characterized the early response genes, including two genes that were specifically responsive to ethanol. We identified a glutamate receptor gene that was induced by ethanol. We also identified a gene encoding a protein with limited homology to human neuroligin that was also specific to ethanol stress.

The second microarray that is available for the nematode biologist is the oligonucleotide DNA chip, in which oligonucleotides are used instead of the cDNAs corresponding to the ORFs (Hill et al., 2000). Using this type of microarray, they were able to measure the absolute level of the transcription of each gene. For example, one can see when in the development a gene of interest is expressed; this information is crucial for deducing the possible functions that this gene might exert.

As soon as one identifies genes that are co-regulated by means of microarrays, one can look for regulatory elements that are conserved among the co-regulated genes. There are many softwares available to deduce conserved motifs in the upstream regions of the co-regulated genes. For example, MEME (Multiple EM for Motif Elicitation; http://meme.sdsc. edu/meme/website/meme.html) is a tool developed by Bailey et al. (1995) for discovering motifs in a group of related DNA 
(A)

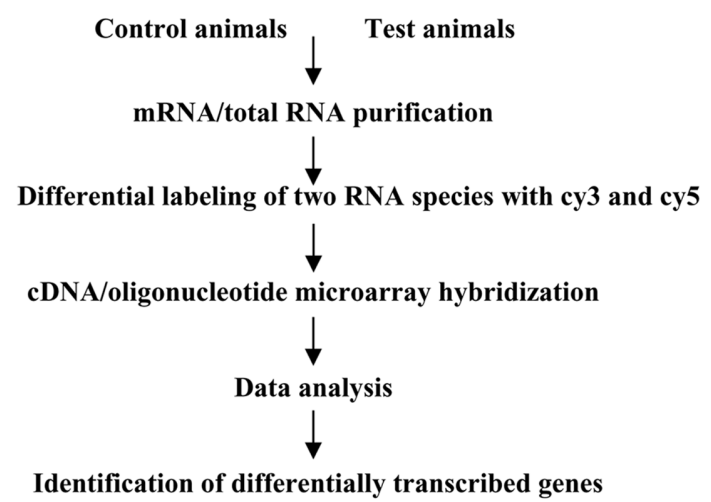

(B)

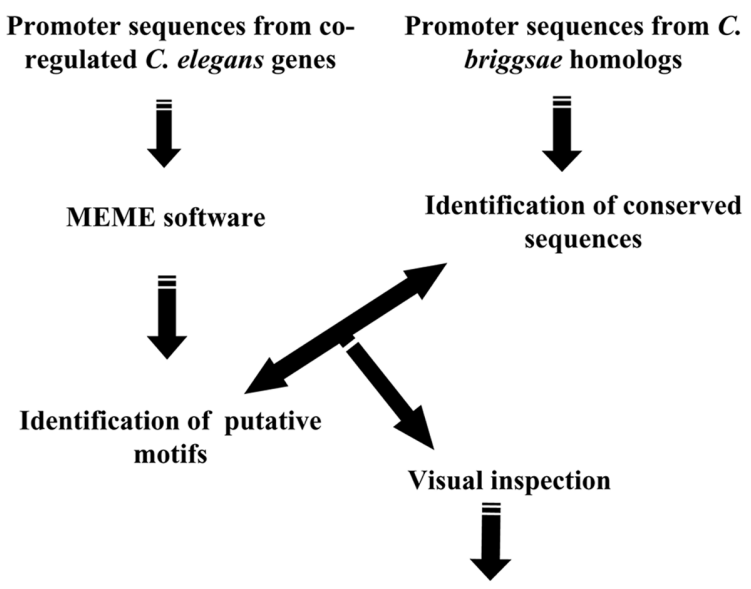

Identification of candidate regulatory elements

Fig. 4. An experimental scheme for microarray experiments. (A) A flow for a typical microarray experiment. RNA is isolated from the control and test animals, differentially labeled, and then the microarray hybridization is performed. The data analysis follows to identify genes that show the co-regulated expression profiles. (B) A schematics showing how to identify regulatory elements for co-regulated genes identified from the microarray experiments. Softwares such as MEME, comparison with the $C$. briggsae homologs, and visual inspection are the crucial steps in this process.

or protein sequences (Bailey and Elkan, 1995). Combining this approach and comparative genomic approaches using the C. briggsae homolog sequence information with the visual inspection of the outcome of the analyses, it is possible to identify regulatory elements in the genes that were shown to be co-regulated (Fig. 4B).

In addition to the use of microarray in the functional studies of $C$. elegans, the microarray data from $C$. elegans was used for abstracting a more grand view of co-regulated gene clusters among different species (Stuart et al., 2003). They identified pairs of genes that are coexpressed over 3182 DNA microarrays from humans, flies, worms, and yeast. In this approach, the authors were able to identify clusters of genes from different species, which showed the pattern of co- regulated expression profiles. It was strongly suggested that the genes that were clustered in the gene family identified by this approach were likely to be co-regulated and may exert common functions in each species.

With more microarray data that are sure to come out in near future, researchers will benefit from them in terms of identifying gene functions and evolutionarily-conserved aspects of genes of their own interest.

\section{Proteomic Approaches}

Although C. elegans is not a good system for biochemical analyses due to protease activities contained in the intestine, thick cuticles and small size of the animal, it is not impossible to employ proteomic approaches for identifying proteins and functions, if one is not afraid of consuming a large number of plates to grow a large number of animals. For example, Choi et al. (2003) performed a proteomic analysis of mixed stage worms whose cholesterol metabolism had been disturbed and found that the proteins levels involved in collagen and cytoskeleton organization were significantly decreased, among other interesting findings. Recently, a few other papers described the proteomic analyses of the $C$. elegans proteome (Hirabayashi et al., 2002; Madi et al., 2003). A limitation to the method involving the whole cell extract for proteomic analyses is that the resolution of the current proteomics technique is insufficient to visualize every protein. It is impossible to see more than 2,000 spots on a 2D gel, missing a large number of less abundant proteins. One way to avoid the problem of the resolution of the current 2D gel electrophoresis would be to perform proteomics with specific protein complexes, not the whole cell extract, whenever possible (Fig. 5). For example, our lab has successfully identified telomere binding proteins by affinity purification and MALDI-TOF analysis (Im and Lee, 2003; Joeng and Lee, in preparation). We had to use 3,000 plates of $100 \mathrm{~mm}$ diameter to harvest about $10 \mathrm{~g}$ of embryos. The nuclear extract from these embryos were applied to the affinity columns containing either double-stranded or single-stranded telomeres, then the eluants were subjected to one-dimensional gel electrophoresis or two-dimensional electrophoresis followed by MALDI-TOF analysis of each spot, or subjected to an LC-MS analysis to determine the identity of the candidate proteins. The outcome of the proteomic analysis was not always satisfactory, because there were many false positives in the following procedures for confirming their real functions. For example, we had many candidates for the double-stranded telomere binding proteins, but so far only one protein was indeed localized to the chromosomal ends in vivo. Other candidates await more thorough analyses, but our preliminary biochemical analyses indicated that these proteins might be non-specific DNA binding proteins. It is crucial to confirm the candidate proteins that come out of any proteomic approach by means of other experimental procedures, such as 


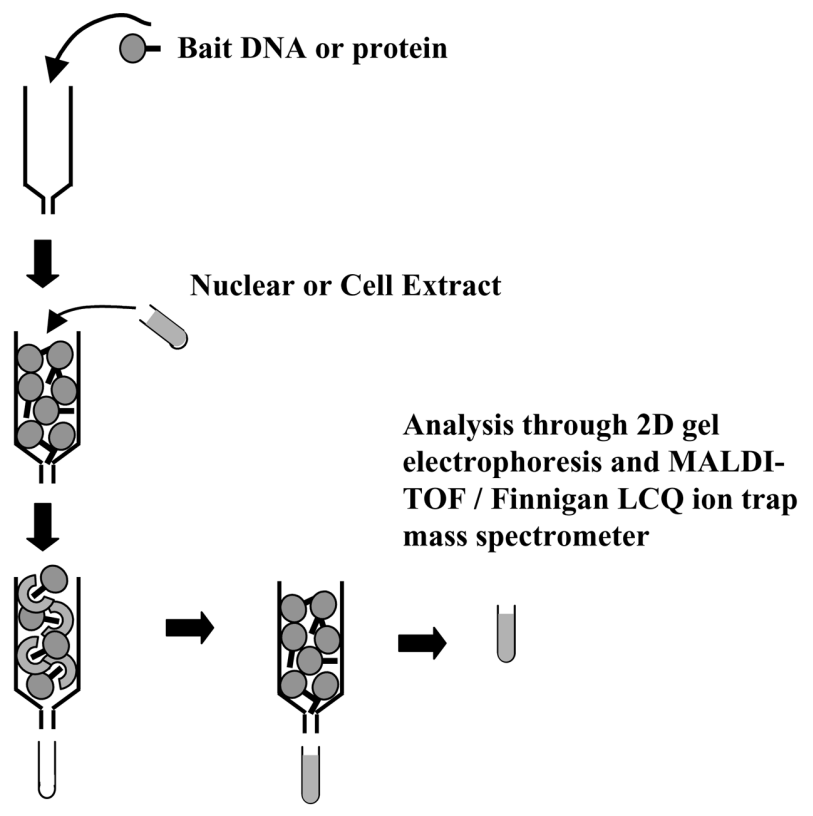

Fig. 5. A schematic drawing of a proteomic approach: affinity purification and MALDI-TOF analysis. The nuclear or the total cell extracts are applied to a column containing the bait DNA or protein, then the elution procedures follow. The eluants are analyzed by 2D gel electrophoresis/MALDI-TOF analysis, or LC-MS analysis.

genetic and biochemical experiments, before further pursuing the functional analyses of the proteins.

\section{Concluding Remarks}

In this review, we tried to show the potential importance of the C. elegans functional genomic approaches in the post genome biology. In addition to the functional genomic approaches that are described in this review, I would like to emphasize that genetics is still a method of choice if one wants to definitively determine the biological functions of a single gene. RNAi has its own limitation in that it does not knock out the gene function, but only knocks it down, and that some tissues such as neurons are not liable to RNAi effects. The ideal method to elucidate the biological function of a gene is to identify a null mutation in this gene and examine the phenotypes that are associated with it. Genetics may sound conventional and conservative, but it is one of the best ways to define the gene networks. To further utilize the genome information for future biology, breakthroughs in techniques are still waiting to be discovered. One way to facilitate genetic approaches is to establish a knockout system in which one can establish a null mutation in a gene of interest by means of homologous recombination, just as in the yeast, the fly, and the mammalian stem cells. Another urgent and desirable system to be established is immortalized cell lines. With cell lines, it would be much easier to perform core biochemical and molecular genetic experiments. In addition, the discovery of a virus that specifically infects the nematode would lead to the establishment of a vector system to deliver a gene of interest into the animals without any laborious micromanipulation. However, it is certain that already established functional genomic approaches expanded the options that a researcher can employ, and it would be up to the researchers which method they would employ to pursue their research goals.

Acknowledgments The works described in this review were supported in part by a National Research Laboratory Grant (M1-0318-00-0053), Molecular Aging Research Grant (02-PJ10-AG01-0010), an KRF grant (2001-015-DP0415), and Biodiscovery Grant (M1-0311-00-0034) to J. Lee.

\section{References}

Ashrafi, K., Chang, F. Y., Watts, J. L., Fraser, A. G., Kamath, R. S., Ahringer, J. and Ruvkun, G. (2003) Genome-wide RNAi analysis of Caenorhabditis elegans fat regulatory genes. Nature 421, 268-272.

Bailey, T. L. and Elkan, C. (1995) The value of prior knowledge in discovering motifs with MEME. Proc. Int. Conf. Intell. Syst. Mol. Biol. 3, 21-29.

Blumenthal, T., Evans, D., Link, C. D., Guffanti, A., Lawson, D., Thierry-Mieg, J., Thierry-Mieg, D., Chiu, W. L., Duke, K., Kiraly, M. and Kim, S. K. (2002) A global analysis of Caenorhabditis elegans operons. Nature 417, 851-854.

Brenner, S. (1974) The genetics of Caenorhabditis elegans. Genetics 77, 71-94.

Choi, B. K., Chitwood, D. J. and Paik, Y. K. (2003) Proteomic changes during disturbance of cholesterol metabolism by Azacoprostane treatment in Caenorhabditis elegans. Mol. Cell Proteomics 2, 1086-1095.

Cui, M. and Han, M. (2003) Cis regulatory requirements for vulval cell-specific expression of the Caenorhabditis elegans fibroblast growth factor gene egl-17. Dev. Biol. 257, 104-116.

Fire, A., Xu, S., Montgomery, M. K., Kostas, S. A., Driver, S. E. and Mello, C. C. (1998) Potent and specific genetic interference by double-stranded RNA in Caenorhabditis elegans. Nature 391, 806-811.

Fraser, A. G., Kamath, R. S., Zipperlen, P., Martinez-Campos, M., Sohrmann, M. and Ahringer, J. (2000) Functional genomic analysis of $C$. elegans chromosome I by systematic RNA interference. Nature 408, 325-330.

Gonczy, P., Echeverri, G., Oegema, K., Coulson, A., Jones, S. J., Copley, R. R., Duperon, J., Oegema, J., Brehm, M., Cassin, E. et al. (2000) Functional genomic analysis of cell division in $C$. elegans using RNAi of genes on chromosome III. Nature 408, 331-336.

GuhaThakurta, D., Palomar, L., Stormo, G. D., Tedesco, P., Johnson, T. E., Walker, D. W., Lithgow, G., Kim, S. and Link, C. D. (2002) Identification of a novel cis-regulatory element involved in the heat shock response in Caenorhabditis elegans using microarray gene expression and computational methods. Genome Res. 12, 701-712.

Heschl, M. F. and Baillie, D. L. (1990) Functional elements and 
domains inferred from sequence comparisons of a heat shock gene in two nematodes. J. Mol. Evol. 31, 3-9.

Hill, A. A., Hunter, C. P., Tsung, B. T., Tucker-Kellogg, G. and Brown, E. L. (2000) Genomic analysis of gene expression in C. elegans. Science 290, 809-812.

Hirabayashi, J., Hayama, K., Kaji, H., Isobe, T. and Kasai, K. (2002) Affinity capturing and gene assignment of soluble glycoproteins produced by the nematode Caenorhabditis elegans. J. Biochem. (Tokyo) 132, 103-114.

Hwang, S. B. and Lee, J. (2003) Neuron cell type-specific SNAP25 expression driven by multiple regulatory elements in the nematode Caenorhabditis elegans. J. Mol. Biol. 333, 237-247.

Im, S. H. and Lee, J. (2003) Identification of HMG-5 as a doublestranded telomeric DNA-binding protein in the nematode Caenorhabditis elegans. FEBS Lett. 554, 455-461.

Kamath, R. S. and Ahringer, J. (2003) Genome-wide RNAi screening in Caenorhabditis elegans. Methods 30, 313-321.

Kamath, R. S., Fraser, A. G., Dong, Y., Poulin, G., Durbin, R., Gotta, M., Kanapin, A., Le Bot, N., Moreno, S., Sohrmann, M. et al. (2003) Systematic functional analysis of the Caenorhabditis elegans genome using RNAi. Nature 421, 231237.

Kim, S. K., Lund, J., Kiraly, M., Duke, K., Jiang, M., Stuart, J. M., Eizinger, A., Wylie, B. N. and Davidson, G. S. (2001) A gene expression map for Caenorhabditis elegans. Science 293, 2087-2092.

Kirouac, M. and Sternberg, P. W. (2003) cis-Regulatory control of three cell fate-specific genes in vulval organogenesis of Caenorhabditis elegans and C. briggsae. Dev. Biol. 257, 85103.

Kuwabara, P. E. and Shah, S. (1994) Cloning by synteny: identifying $C$. briggsae homologues of $C$. elegans genes. Nucleic Acids Res. 22, 4414-4418.

Kwon, J., Hong, M., Choi, M., Kang, S., Duke, K., Kim, S., Lee, S. and Lee, J. (2004) Ethanol response genes and their regulation analyzed by microarray and comparative genomic approach in the nematode Caenorhabditis elegans. Genomics in press.

Lee, S. S., Lee, R. Y., Fraser, A. G., Kamath, R. S., Ahringer, J. and Ruvkun, G. (2003) A systematic RNAi screen identifies a critical role for mitochondria in C. elegans longevity. Nat. Genet. 33, 40-48.

Link, C. D., Taft, A., Kapulkin, V., Duke, K., Kim, S., Fei, Q., Wood, D. E. and Sahagan, B. G. (2003) Gene expression analysis in a transgenic Caenorhabditis elegans Alzheimer's disease model. Neurobiol. Aging 24, 397-413.

Madi, A., Mikkat, S., Ringel, B., Ulbrich, M., Thiesen, H. J. and Glocker, M. O. (2003) Mass spectrometric proteome analysis for profiling temperature-dependent changes of protein expression in wild-type Caenorhabditis elegans. Proteomics 3,
1526-1534.

Maeda, I., Kohara, Y., Yamamoto, M. and Sugimoto, A. (2001) Large-scale analysis of gene function in Caenorhabditis elegans by high- throughput RNAi. Curr. Biol. 11, 171-176.

Murphy, C. T., McCarroll, S. A., Bargmann, C. I., Fraser, A., Kamath, R. S., Ahringer, J., Li, H. and Kenyon, C. (2003) Genes that act downstream of DAF-16 to influence the lifespan of Caenorhabditis elegans. Nature 424, 277-283.

Piano, F., Schetter, A. J., Mangone, M., Stein, L. and Kemphues, K. J. (2000) RNAi analysis of genes expressed in the ovary of Caenorhabditis elegans. Curr. Biol. 10, 1619-1622.

Reinke, V. (2002) Functional exploration of the C. elegans genome using DNA microarrays. Nat. Genet. 32 Suppl, 541546.

Reinke, V., Smith, H. E., Nance, J., Wang, J., Van Doren, C., Begley, R., Jones, S. J., Davis, E. B., Scherer, S., Ward, S. and Kim, S. K. (2000) A global profile of germline gene expression in C. elegans. Mol. Cell 6, 605-616.

Romagnolo, B., Jiang, M., Kiraly, M., Breton, C., Begley, R., Wang, J., Lund, J. and Kim, S. K. (2002) Downstream targets of let-60 Ras in Caenorhabditis elegans. Dev. Biol. 247, 127136.

Simmer, F., Moorman, C., Van Der Linden, A. M., Kuijk, E., Van Den Berghe, P. V., Kamath, R., Fraser, A. G., Ahringer, J. and Plasterk, R. H. (2003) Genome-wide RNAi of C. elegans using the hypersensitive $r r f-3$ strain reveals novel gene functions. PLoS Biol. 1, E12.

Stein, L. D., Bao, Z., Blasiar, D., Blumenthal, T., Brent, M. R., Chen, N., Chinwalla, A., Clarke, L., Clee, C., Coghlan, A. et al. (2003) The genome sequence of Caenorhabditis briggsae: A platform for comparative genomics. PLoS Biol. 1, E45.

Stuart, J. M., Segal, E., Koller, D. and Kim, S. K. (2003) A genecoexpression network for global discovery of conserved genetic modules. Science 302, 249-255.

Tabara, H., Grishok, A. and Mello, C. C. (1998) RNAi in C. elegans: soaking in the genome sequence. Science 282, 430431.

Tavernarakis, N., Wang, S. L., Dorovkov, M., Ryazanov, A. and Driscoll, M. (2000) Heritable and inducible genetic interference by double-stranded RNA encoded by transgenes. Nat. Genet. 24, 180-183.

Timmons, L. and Fire, A. (1998) Specific interference by ingested dsRNA. Nature 395, 854.

Wang, J. and Kim, S. K. (2003) Global analysis of dauer gene expression in Caenorhabditis elegans. Development 130, 16211634.

Zhang, Y., Ma, C., Delohery, T., Nasipak, B., Foat, B. C., Bounoutas, A., Bussemaker, H. J., Kim, S. K. and Chalfie, M. (2002) Identification of genes expressed in C. elegans touch receptor neurons. Nature 418, 331-335. 